\title{
Knowledge about iodine requirements during pregnancy and breastfeeding among pregnant women living in Northern Ireland
}

\author{
Paul McMullan ${ }^{1}$, Alyson Hunter ${ }^{3}$, David McCance ${ }^{1}$, Jayne V. Woodside ${ }^{2^{*}}$ (D) and Karen Mullan ${ }^{1}$
}

\begin{abstract}
Background: lodine is an essential micronutrient important for foetal nerve and brain development, especially in the early stages of pregnancy. The re-emergence of mild to moderate iodine deficiency has recently been reported in the United Kingdom (UK). The level of knowledge amongst pregnant women regarding iodine nutrition is poorly understood. The aim of this study was to determine the level of knowledge about iodine nutrition during pregnancy among pregnant women living in Northern Ireland (NI).

Methods: A cross-sectional study in pregnant women was carried out in Royal Jubilee Maternity Hospital Belfast, from March to June 2015. Two hundred pregnant women were provided with a short questionnaire on iodine knowledge during routine clinic visits and comparisons were made across trimester and parity.

Results: Only $20 \%$ of women were aware of the potentially increased iodine requirements during pregnancy and breast feeding; $45 \%$ were unable to identify any foods they thought would be iodine rich. The three main sources of dietary iodine in the UK are fish, dairy and eggs and 30, 9 and 15\% correctly identified these as good sources respectively. When asked about whether they felt they had been given sufficient advice about folic acid and iodine in pregnancy, $90 \%$ felt this was so for folic acid, but only $5 \%$ for iodine.

Conclusions: This study suggests that iodine knowledge among pregnant women living in $\mathrm{NI}$ is poor. In the absence of any iodine fortification programme, women in the UK may be vulnerable to iodine deficiency in pregnancy. At present they are poorly equipped to make positive dietary changes to meet their increasing iodine requirements during pregnancy and breastfeeding. Public health strategies should be considered to target this population group.
\end{abstract}

Keywords: lodine, Knowledge, Nutrition, Pregnancy, Breastfeeding, Thyroid

\section{Background}

Iodine is an essential trace element required for production of thyroid hormones, and an increased supply of dietary iodine is of particular importance during pregnancy to compensate for foetal requirements [1]. Within the United Kingdom (UK) and Ireland, since the 1930s when iodine started to be added to cattle feed and successive UK governmemnts encouraged milk consumption in schoolchildren, iodine intakes were thought to be adequate. More

\footnotetext{
* Correspondence: j.woodside@qub.ac.uk

${ }^{2}$ Centre for Public Health, School of Medicine, Dentistry and Biomedical

Science, Queen's University Belfast, Belfast, UK

Full list of author information is available at the end of the article
}

recently, a survey reported iodine levels in teenage girls from the UK [2]. Results suggested that this group were mildly iodine deficient and that milk consumption positively correlated with iodine status as measured by urinary iodine concentration (UIC). Data from the Republic of Ireland (ROI) also indicated mild deficiency in the general population in the 1990s and, more recently, in pregnancy $[3,4]$. Worldwide it is estimated that 1.9 billion people are affected by iodine deficiency [5].

Iodine is found in a range of foods, with the richest sources being fish and dairy products. Within Ireland and the UK, milk and dairy products tend to be the main sources of dietary iodine, $[6,7]$. The UK and ROI

(c) The Author(s). 2019 Open Access This article is distributed under the terms of the Creative Commons Attribution 4.0 International License (http://creativecommons.org/licenses/by/4.0/), which permits unrestricted use, distribution, and reproduction in any medium, provided you give appropriate credit to the original author(s) and the source, provide a link to the Creative Commons license, and indicate if changes were made. The Creative Commons Public Domain Dedication waiver (http://creativecommons.org/publicdomain/zero/1.0/) applies to the data made available in this article, unless otherwise stated. 
have no formal iodine fortification programme in place, so that iodine status depends entirely on dietary intake from naturally occurring sources. This contrasts with many European countries and Australia which have a programme of salt iodization in place [8].

There are no UK specific recommendations on iodine supplementation or fortification during pregnancy, despite international guidelines (WHO 2007) [5]. The Scientific Advisory Committee on Nutrition (SACN) has advised no change to the status quo in the UK, pending further research [9].

Little is known if women themselves are aware of the importance of iodine in the perinatal period and if they are able to identify foods that are rich in iodine. In Northern Ireland (NI) 'The Pregnancy Book' is offered to all pregnant women [10]. Information is provided on folic acid, vitamin $\mathrm{D}$, iron, vitamin $\mathrm{C}$ and calcium but does not mention iodine nor does it recommend iodine as supplement. The British Dietetics Association has produced a factsheet on iodine specifically for pregnant women, although awareness or uptake of this is uncertain [11]. There is a paucity of studies looking at iodine knowledge among pregnant women but those that are available point to clear gaps in knowledge. The aim of the study was to determine the level of knowledge about iodine nutrition during pregnancy among pregnant women living in Northern Ireland.

\section{Methods}

\section{Subjects}

Recruitment and data collection were carried out in the Royal Jubilee Maternity Hospital, Belfast Health and Social Care Trust between March and June 2015. Ethical approval was obtained from the Office of Research Ethics Committees Northern Ireland (Ref 14/NI/0047) and Governance approval from the Belfast Health and Social Care Trust (ref 13171KM-AS).

\section{Data collection}

Two hundred questionnaires were distributed during routine antenatal clinics or education sessions by a member of the research team who explained the purpose of the questionnaire and offered a paper copy to those who provided consent.These clinics and visits occurred across trimesters. The numbers recruited were based on previous comparable questionnaire studies [12-14]. Consent was verbal and confirmed by completing and submitting the questionnaire. The questionnaire was self-completed without help and there were no inclusion /exclusion criteria beyond pregnancy. All participants were attending regular adult services and no children or vulnerable adults were approached. No personal information was collected from the questionnaire and data were fully anonymised. The questionnaire was set out in format in a similar way to previously reported questionnaires and checked for ease and clarity of instruction by 10 lay women (4 of whom were pregnant) $[12,13]$. This is provided in the Additional file 1 section.

\section{Statistical analysis}

Statistical analyses were conducted using the Statistical Package for the Social Sciences software (version 23.0; SPSS, Inc. USA) and significance set at $p<0.05$. Non parametric testing was used in view of nominal and ordinal results from the questionnaire, with Mann-Whitney and Kruskall-Wallis tests used to compare results for 2 or $\geq 2$ groups respectively. Data were presented using descriptive statistics and comparisons in responses among women at different stages and number of pregnancies were made.

\section{Results}

A total of 183/200 (91.5\%) completed and returned the questionnaire. Of these 59\% were nulliparous. Most were in later stages of pregnancy with a breakdown of 4, 33 and $63 \%$ in 1st to 3rd trimester respectively. When asked to identify which gland iodine is needed for, $28 \%$ correctly identified the thyroid gland with $59 \%$ not sure. There was no significant difference in responses either between nulliparous and multiparous women or between trimesters. When asked to identify foods be rich in iodine nearly half of participants were not sure (Table 1).

The three main sources of dietary iodine in the UK are fish, dairy and eggs and 30, 9 and 15\% correctly identified these as good sources respectively. Nulliparous women were less likely than multiparous women to identify seafood as a good source of iodine (22\% vs $49 \%)$ $(p=0.006)$ but otherwise there were no differences between these two groups. There were no significant differences by trimester in the identification of the iodine rich foods.

Table 1 Responses to which foods are considered good sources of iodine

\begin{tabular}{|c|c|c|}
\hline Food selected & $n$ & $\%$ \\
\hline Not sure & 83 & 45 \\
\hline Seafood/fish ${ }^{\mathrm{a}}$ & 55 & 30 \\
\hline Vegetables & 44 & 24 \\
\hline Meat & 42 & 23 \\
\hline Eggs $^{a}$ & 28 & 15 \\
\hline Fruit & 25 & 14 \\
\hline Bread & 18 & 10 \\
\hline Dairy $^{a}$ & 17 & 9 \\
\hline Salt & 14 & 8 \\
\hline Poultry & 10 & 6 \\
\hline Soya milk & 9 & 5 \\
\hline
\end{tabular}

${ }^{\mathrm{a}}$ Sources rich in iodine in UK 
Participants were asked "What happens to your iodine requirements during pregnancy and [breastfeeding]?" The majority were unsure for both pregnancy and breastfeeding while only $\sim 20 \%$ answered correctly that iodine requirements increase during both periods (Table 2). There were no significant differences with parity or trimester in how women answered these questions. When asked of the effects of iodine deficiency, $5 \%$ of participants answered that they believed it to be harmful nearly half were unsure. No differences were seen between nulliparous and multiparous women or between trimesters. When asked "Can you have too much iodine in your diet?" the majority again were not sure especially among the nulliparous group (78\% vs $59 \%)(p=0.007)$ although there was no difference between trimesters (data not shown).

Participants graded the information given to them about folic acid, iron, calcium, vitamin $\mathrm{D}$ and iodine using a five point Likert scale (Table 3).

The numbers of participants agreeing/strongly agreeing that adequate information was provided was highest for folic acid (89\%) and lowest for iodine (5\%). No differences were observed in response to this question when analysed by parity or trimester stage. Table 4 lists all the statements made in the comment section of the questionnaire.

Table 2 Awareness of changes in iodine requirements during pregnancy and breast feeding and of harmful effects of deficient and excess iodine in the diet

\begin{tabular}{lll}
\hline Requirements? & $n$ & $\%$ \\
\hline During Pregnancy & 39 & 22 \\
-Increase & 29 & 16 \\
-Decrease & 3 & 2 \\
-Same & 108 & 60 \\
-Not sure & & \\
During Lactation & 37 & 21 \\
-Increase & 16 & 9 \\
-Decrease & 3 & 2 \\
-Same & 123 & 69 \\
-Not sure & & \\
Harmful effects? & & 5 \\
Deficiency & 9 & 50 \\
-Yes & 89 & 45 \\
-No & 82 & 3 \\
-Not sure & & 27 \\
Excess & 5 & 70 \\
-Yes & 49 & \\
-No & 127 & \\
-Not sure & & \\
\hline
\end{tabular}

Table 3 Responses on a 5 point Likert scale for information adequacy during pregnancy regarding selected nutrients

\begin{tabular}{lll}
\hline Nutrient & $n$ & $\%$ \\
\hline Folic acid & 9 & 7 \\
-Strongly disagree/Disagree & 6 & 4 \\
-Neither & 164 & 89 \\
-Agree/ Strongly agree & & 13 \\
Iron & 22 & 11 \\
-Strongly disagree/ Disagree & 19 & 76 \\
-Neither & 137 & 23 \\
-Agree/ Strongly agree & & 12 \\
Vitamin D & 39 & 65 \\
-Strongly disagree/ Disagree & 20 & \\
-Neither & 118 & 19 \\
-Agree/ Strongly agree & & 14 \\
Calcium & 31 & 67 \\
-Strongly disagree/ Disagree & 24 & 76 \\
-Neither & 118 & 5 \\
-Agree/ Strongly agree & & \\
lodine & 129 & \\
-Strongly disagree/ Disagree & 31 & \\
-Neither & 7 & \\
-Agree/ Strongly agree & & \\
\hline
\end{tabular}

\section{Discussion}

Our study findings are consistent with the two other studies available in the UK which show that knowledge around iodine in pregnant women is low. Table 5 compares recent studies in pregnant women and results are consistent over the last ten years. Knowledge was also deficient in a recent Norwegian cohort although a voluntary iodine fortification programme is in place which may mitigate against this to some extent [15]. A cohort from Australia also showed significant knowledge gaps among this vulnerable group but a mandatory fortification programme there is likely to counterbalance the lack of knowledge among this particular population [13].

Women report poor understanding of the importance of iodine in pregnancy, are inaccurate at identifying foods rich in iodine and are not confident about how to best optimise iodine intake in pregnancy. A similar study, but in non-pregnant women in the UK, was also consistent with these findings with $41 \%$ of participants unable to identify any health problem related to iodine deficiency [16].

Although knowledge regarding the importance of iodine is limited, motivation among women to make appropriate dietary changes in pregnancy is high as demonstrated in a qualitative paper on iodine in pregnancy conducted in 48 perinatal women in the UK [14]. The study also reported 
Table 4 Responses for requests for any comments

\begin{tabular}{|c|c|}
\hline & Comment \\
\hline 1 & "Don't know anything about iodine" \\
\hline 2 & $\begin{array}{l}\text { "Have pregnancy book which possibly provides more } \\
\text { info on nutrients but I believe folic acid is promoted } \\
\text { more than other nutrients obviously due to it being } \\
\text { more vital in early pregnancy I believe" }\end{array}$ \\
\hline 3 & $\begin{array}{l}\text { "I did my own research into vitamin D but not know } \\
\text { iodine was essential" }\end{array}$ \\
\hline 4 & $\begin{array}{l}\text { "I feel a lot of things are assumed and any info about } \\
\text { nutrients has been by chance" }\end{array}$ \\
\hline 5 & $\begin{array}{l}\text { "I have never had iodine mentioned to me since I fell } \\
\text { pregnant and no information" }\end{array}$ \\
\hline 6 & $\begin{array}{l}\text { "I have not been made aware of the significance of } \\
\text { iodine during pregnancy" }\end{array}$ \\
\hline 7 & $\begin{array}{l}\text { "I haven't read anything about iodine despite reading } \\
\text { about diet in pregnancy" }\end{array}$ \\
\hline 8 & "lodine - not sure what this is" \\
\hline 9 & "lodine never discussed" \\
\hline 10 & $\begin{array}{l}\text { "lodine was never explicitly mentioned but I did say I } \\
\text { took pregnacare so I would guess that covers it" }\end{array}$ \\
\hline 11 & "More info needed" \\
\hline 12 & "Never had iodine mentioned at all" \\
\hline 13 & $\begin{array}{l}\text { "I thought iodine was bad for the baby's development } \\
\text { I didn't think of it as something you should take" }\end{array}$ \\
\hline 14 & $\begin{array}{l}\text { "I have been told nothing about iodine during this } \\
\text { pregnancy. I have gestational diabetes and this was } \\
\text { not mentioned as an issue" }\end{array}$ \\
\hline 15 & "Really don't know much about this sorry" \\
\hline 16 & "They ask loads of questions but give no feedback" \\
\hline
\end{tabular}

a desire by those in the perinatal period to have user friendly communication and involvement of health services to support these changes.

Although countries outside of the UK have shown similar low levels of knowledge, the UK population may be more vulnerable to possible iodine deficiency in pregnancy $[13,15]$. The UK is one of twelve countries within the block of forty European countries which has no legislation for mandatory or voluntary iodine fortification [17]. We have recently reported in abstract form, iodine deficiency throughout all trimesters in 241 pregnant women from NI, which is separate cohort from that described in this paper [18]. This was despite $53 \%$ of women taking a pregnancy related supplement containing iodine.

It is interesting that broadly speaking, neither advanced trimester nor parity affected knowledge levels in our study and this would fit with a pattern of lack of accessible information for our pregnant women. The comments centre around a lack of information provided by health care providers and pregnancy literature provided. This contrasts markedly with adequacy of information regarding folic acid. The "Pregnancy Book" given to all pregnant women in NI discusses folic acid and advises supplementation of folic acid and vitamin $\mathrm{D}$ but fails to mention iodine. Bouga et al. points to community midwives as the main source of dietary advice in pregnancy in the UK but the advice received focussed on multivitamin supplements rather than food choices [14].

A recent Australian survey of 329 midwives reported that the majority rated both the importance of nutrition and the significance of their role in nutrition education as high [19]. Indeed the vast (93\%) provided nutrition advice but their level of confidence in discussing nutrition issues ranged from low to moderate. Only half reported receiving nutrition education during their undergraduate or postgraduate careers. When asked about iodine requirements $80 \%$ gave incorrect responses.

Dietary knowledge about iodine has not always been shown to lead to significantly improved iodine status. O'Kane et al. reported that greater iodine knowledge

Table 5 lodine knowledge studies among pregnant women

\begin{tabular}{|c|c|c|c|c|c|c|}
\hline Location & Years & No. & Cohort & Knowledge indexes & Scores & \\
\hline $\begin{array}{l}\text { Australia } \\
\text { Charlton et al [13] }\end{array}$ & $2007-8$ & 139 & Pregnant & Identify milk as a source of I & $26 \%$ & \\
\hline \multirow{3}{*}{$\begin{array}{l}\text { UK } \\
\text { Combet et al [12] }\end{array}$} & & & & Identify milk as a source of I & $9 \%$ & \\
\hline & $2011-2$ & 305 & Pregnant & Awareness of I guidance & $12 \%$ & \\
\hline & & 721 & Postpartum & Confidence to optimise I & $28 \%$ & \\
\hline \multirow{2}{*}{$\begin{array}{l}\text { UK } \\
\text { Ref: [14] Bouga et al }\end{array}$} & & & & Confidence to optimise I & $29 \%$ & \\
\hline & 2015 & 48 & Perinatal & lodine awareness & $23 \%$ & \\
\hline \multirow{3}{*}{$\begin{array}{l}\text { Norway } \\
\text { Gardweidner-Holme et al [15] }\end{array}$} & & & & & $P$ & $L$ \\
\hline & 2016 & 804 & Pregnant & Identify milk as a source of I & $29 \%$ & $54 \%$ \\
\hline & & 175 & Lactating & lodine knowledge score ${ }^{a}$ & $26 \%$ & $45 \%$ \\
\hline \multirow[t]{2}{*}{ N Ireland } & & & & Identify dairy as source of I & $9 \%$ & \\
\hline & current & 183 & Pregnant & Adequacy of I information & $5 \%$ & \\
\hline
\end{tabular}

${ }^{\mathrm{a}}$ Self-reported on a scale (none: poor: low: medium: high); $P$ Pregnant, $L$ Lactating 
scores were positively associated with a higher dietary intake of iodine in a non-pregnant population, as measured by a food frequency questionnaire (FFQ) [16]. However Garnweidner-Holme et al. reported no association between knowledge scores and iodine status in a pregnant/lactating cohort as demonstrated by the gold standard UIC [15]. They also reported that higher educated women and those who had received information about iodine had higher knowledge scores.

Public health strategies should be considered to increase awareness of the importance of iodine in pregnancy in this population group. Promotion of the BDA food fact sheet about iodine may be a good first step in this process although this may be an insufficient measure without a food fortification programme. Further work re iodine optimisation in this group is warranted.

This study has a number of limitations. Data on age, socio-economic status, education level and provision of any previous pregnancy nutritional education were not collected. No information was collected on those that did not complete the questionnaire or who did not want to take part. Those with poor nutritional knowledge may have declined completing this questionnaire potentially affecting results. All data were self-reported with the possibility of reporter bias but this pertains to all similar studies. Data on iodine knowledge among local midwives were not examined in parallel with this cohort and may be an interesting avenue as we endeavour to develop strategies to improve iodine nutrition in pregnancy.

\section{Conclusions}

This study suggests that dietary iodine knowledge among pregnant women living in NI is poor. In the absence of any iodine fortification programme, women in the UK may be vulnerable to iodine deficiency in pregnancy. At present they are poorly equipped to make positive dietary changes to meet their increasing iodine requirements during pregnancy and breastfeeding.

\section{Additional file}

Additional file 1: Questionnaire. lodine Knowledge Questionnaire. Copy of questionnaire provided in study. (PDF $125 \mathrm{~kb}$ )

\section{Abbreviations}

BDA: British Dietetic Association; NI: Northern Ireland; ROI: Republic of Ireland; SACN: Scientific Advisory Committee on Nutrition; SPSS: Statistical package for the Social Sciences; UIC: Urinary iodine concentration; UK: United Kingdom; WHO: World Health Organisation

\section{Acknowledgements}

$\mathrm{N} / \mathrm{a}$

\section{Funding}

Metabolic Research Fund, Royal Victoria Hospital Belfast. The funding body had no input into the design of the study; collection, analysis, and interpretation of data; or in writing the manuscript.

\section{Availability of data and materials}

The datasets used and/or analysed during the current study are available from the corresponding author on reasonable request.

\section{Authors' contributions}

PM designed the study, performed data collection and analysis and wrote the first draft of the manuscript, AH facilitated patient recruitment and advised on data collection and analysis, DM advised on data collection and analysis, JW designed the study, advised on data collection and analysis and revised the manuscript, KM designed the study, advised on data collection and analysis and revised the manuscript. All authors have read and approved the final version of the manuscript.

\section{Ethics approval and consent to participate}

Ethical approval was obtained from Office of Research Ethics Committees Northern Ireland (Ref 14/NI/0047) and Governance approval from the Belfast Health and Social Care Trust (ref 13171KM-AS). Consent was provided verbally and this method was approved by the ethics committee.

Consent for publication

$\mathrm{N} / \mathrm{a}$ as no personal data included in the manuscript.

\section{Competing interests}

The authors declare that they have no competing interests.

\section{Publisher's Note}

Springer Nature remains neutral with regard to jurisdictional claims in published maps and institutional affiliations.

\section{Author details}

${ }^{1}$ Regional Centre for Endocrinology and Diabetes, Royal Victoria Hospital Belfast, Belfast, UK. ${ }^{2}$ Centre for Public Health, School of Medicine, Dentistry and Biomedical Science, Queen's University Belfast, Belfast, UK. ${ }^{3}$ Royal Maternity Hospital Belfast, Belfast, UK.

Received: 13 December 2018 Accepted: 25 February 2019

Published online: 12 March 2019

\section{References}

1. Pearce EN, Lazarus JH, Moreno-Reyes R, Zimmermann MB. Consequences of iodine deficiency and excess in pregnant women: an overview of current knowns and unknowns. Am J Clin Nutr. 2016;104(Suppl 3):918S-23S.

2. Vanderpump MP, Lazarus JH, Smyth PP, Laurberg P, on behalf of the British Thyroid Association UK lodine Survey Group, et al. lodine status of UK schoolgirls: a cross-sectional survey. Lancet. 2011;377:2007-12.

3. Lazarus JH, Smyth PP. lodine deficiency in the UK and Ireland. Lancet. 2008; 372:888.

4. Nawoor Z, Burns R, Smith DF, Sheehan S, O'Herlihy C, Smyth PP. Iodine intake in pregnancy in Ireland-a cause for concern? Ir J Med Sci. 2006;175:21-4.

5. WHO. Assessment of iodine deficiency disorders and monitoring their elimination; 2007; $3^{\text {rd }}$ edition.

6. Food Standards Agency (2008) Retail survey of iodine status in UK produced dairy foods. FSIS02/08. https://webarchive.nationalarchives.gov.uk/ 20120403220603/http:/www.food.gov.uk/multimedia/pdfs/fsis0208.pdf.

7. Bath SC, Button S, Rayman MP. Iodine concentration of organic and conventional milk: implications for iodine intake. Br J Nutr. 2012;107:935-40.

8. Andersson M, De Benoist B, Darnton-Hill I, Delange F. Iodine deficiency in Europe: a continuing public health problem. Geneva: World Health Organization; 2007.

9. SACN. 12/07. lodine and Health. https://www.gov.uk/government/publications/ sacn-statement-on-iodine-and-health-2014 (last accessed 30/10/18).

10. The Pregnancy Book. http://www.publichealth.hscni.net/publications/ pregnancy-book-0 (last accessed 30/10/18).

11. BDA lodine factsheet. https:/www.bda.uk.com/foodfacts/lodine.pdf (last accessed 30/10/18).

12. Charlton K, Yeatman H, Lucas C, Axford S, Gemming L, Houweling F, Goodfellow A, Ma G. Poor knowledge and practices related to iodine nutrition during pregnancy and lactation in Australian women: pre- and post-iodine fortification. Nutrients. 2012;4(9):1317-27. 
13. Combet E, Bouga M, Pan B, Lean ME, Christopher CO. lodine and pregnancy a UK cross-sectional survey of dietary intake, knowledge and awareness. Br J Nutr. 2015;114(1):108-17.

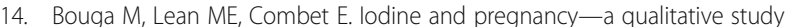
focusing on dietary guidance and information. Nutrients. 2018;10(4):408.

15. Garnweidner-Holme L, Aakre I, Lilleengen AM, Brantsæter AL, Henjum S. Knowledge about iodine in pregnant and lactating women in the Oslo area, Norway. Nutrients. 2017;9(5).

16. O'Kane SM, Pourshahidi LK, Farren KM, Mulhern MS, Strain JJ, Yeates AJ. lodine knowledge is positively associated with dietary iodine intake among women of childbearing age in the UK and Ireland. Br J Nutr. 2016;18:1-8.

17. Iodine deficiency in Europe. A continuing Public Health problem. 2007. https://www.who.int/nutrition/publications/micronutrients/iodine deficiency/9789241593960/en/ (last accessed 30/10/18)

18. McMullan P, Hamill L, McCance D, Woodside J Mullan K. lodine nutritional status among pregnant women and their offspring in Northern Ireland (NI). Presented at Society for Endocrinology BES, Brighton, UK Endocr Abstr 201644 OC6.4

19. Arrish J, Yeatman H, Williamson M. Australian midwives and provision of nutrition education during pregnancy: a cross sectional survey of nutrition knowledge, attitudes, and confidence. Women Birth. 2016;29(5):455-64.

Ready to submit your research? Choose BMC and benefit from:

- fast, convenient online submission

- thorough peer review by experienced researchers in your field

- rapid publication on acceptance

- support for research data, including large and complex data types

- gold Open Access which fosters wider collaboration and increased citations

- maximum visibility for your research: over $100 \mathrm{M}$ website views per year

At BMC, research is always in progress.

Learn more biomedcentral.com/submissions 